\title{
"Critical Analysis of Vibration Behaviourof Multi-Leaf Spring under Loading Condition by ANSYS Software"
}

\author{
Karan K. Sharma ${ }^{1}$, Arshad Rashid ${ }^{2}$, Saiprasad Mandale ${ }^{3}$ \\ 1, 2, 3 (Assistant Professor, MMANTC, Malegaon)
}

\begin{abstract}
The objective of this paper is to analyze the leaf spring for the constraints such as material composition, vibrations developed in the springs. Vibration analysis plays a very important role in the design of steel leaf spring, since the failure due to vibration is more prominent rather than material failure. In this paper an attempt has been made to predict the vibration behavior of leaf spring under dynamic forces and to check the suitability of steel material.The FE model of the leaf spring has been generated inPro-e and imported in ANSYS14 for finite element analysis, which are most popular CAE tools. The FE analysis of the leaf spring has been performed by discretization of the model in infinite nodes and elements and refining them under defined boundary condition. The analytical results are compared with experimentalresults and verified.
\end{abstract}

Keywords: Leaf Spring, FEA, frequency response, vibration,etc.

\section{Introduction}

Leaf springs are commonly used in the vehicle suspension system and are subjected to millions of varying stress cycles leading to fatigue failure. A lot of research has been done for improving the performance of leaf spring. The automobile industry has shown interest in the replacement of steel spring with composite leaf spring. The automobile manufacturers can reduce product development cost and time while improving the safety, comfort, and durability of the vehicles they produce with this analysis. Also during the analysis, the leaf spring is subjected to frequency with which the leaf spring has to operate most of the times in the vehicles. The aim of this paper is to represent a general study on the design, analysis of leaf spring. Nevertheless, we usually reserve the word SPRING to mean a machine element whose primary function is to undergo relatively large deflection of some kind, thereby storing a relatively large amount of strain energy.Depending on the application, it may also be important to be able either to recover the stored energy without excessive losses, or to absorb (or dissipate) as much of the stored energy as possible in order to prevent rebound.In other applications, such as vibration absorption, it is of advantage to have the absorbed energy dissipated within the spring the characteristics of a material such as rubber or polymer.The energy storage mode is important for a number of reasons and will vary to suit the application.

Sugiyama et al. [1] suggests that existing leaf spring models can roughly be classified into three categories; (1) a lumped spring model, (2) a discretized model, where a number of rigid links, connected by springs and dampers, are used to account for the structural flexibility of the spring blades and (3) finite element models.

Fancheret al. [2]measured the force-producing characteristics of several different types of leaf springs while exciting them at various amplitudes and frequencies of oscillation about nominal loading conditions and develop a means for representing the force deflection characteristics of leaf springs in a form suitable for use in simulations of commercial vehicles.

Cebonet al.[3] describes an experimental investigation into the behavior of some typical leaf springs for realistic operation conditions.

Hoyleet al.[4] extended his leaf spring model to include the relaxation and recovery regimes generated by the rubber bushes used in the suspension system. This was modeled as a spring in series with a damper/coulombfriction element.

Erdogan KILIC et al. [6] present a leaf spring model that can be used in road load simulations. They model the leaf spring in a similar way to the model .The model parameters are identified from static force-deflection test data.

C.K. Clarke and G.E. Borowski et al. [7] report a systematic methodology which is used to evaluate and improve vehicle ride comfort. The vehicle dynamics model of a tractor with tandem suspension is modelled and simulated in ADAMS.

S. S. Raoet al.[15] presents a finite element algorithm to address the contact problem encountered in multi-leaf springs.

O.P.Khanna et al.[17]model the multi-leaf spring as four links with two torsional springs, two bushings and a revolute joint. They state that when modelled in this way the model can represent the behaviour of a multi-leaf spring even when a braking force is applied to the wheel. 
Autar.K.Kawet al.[18] state that their experience with the 3 link leaf spring model is that it has difficulty predicting the lateral loads accurately. One of the reasons they contribute the lack of accuracy to, is that the 3 link leaf spring model cannot represent the roll behaviour of the actual suspension very well.

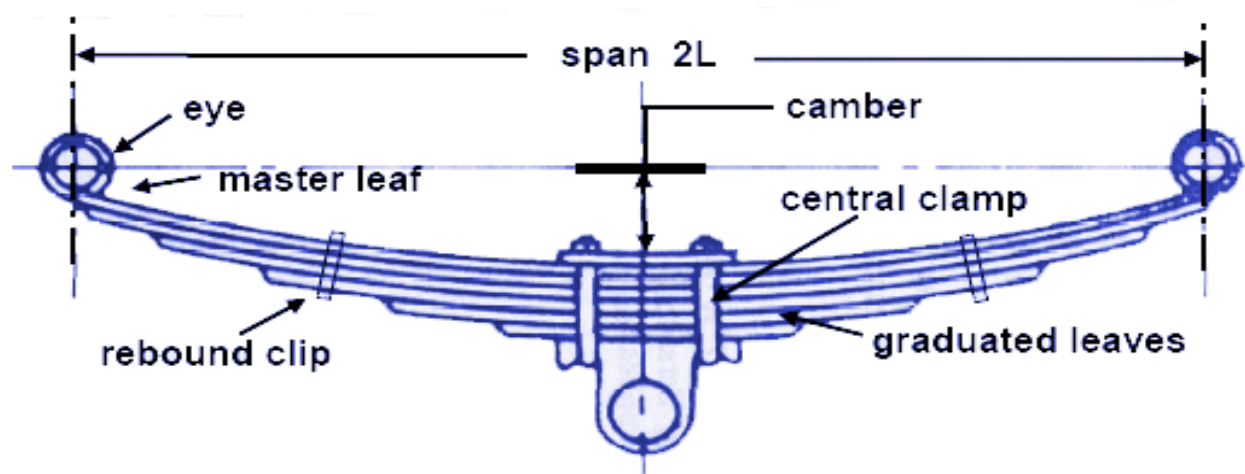

Figure-1 Leaf Spring

\section{A. Objective of Project:}

\section{Methodology}

The main objectives of present paper are:-

1. To carry out finite element analysis of composite leaf spring and analytical validation of it.

2. To study vibration characteristic of leaf spring. The leaf spring should absorb the vertical vibrations and impacts due to road irregularities by means of variations in the spring deflection so that the potential energy is stored in spring as strain energy and then released slowly. So, increasing the energy storage capability of a leaf spring ensures a more compliant suspension system.

3. Modelling the leaf spring without losing its geometry in Pro/engineer software.

4. Analyse and Compare the various stresses, strain and safety factors of the model of Leaf Spring FEM tool ANSYS.

5. Perform parametric study to study the effect of varying load on the various stresses, strains on the Leaf Spring Model.

\section{B. Specification of The Leaf Spring}

The test steel leaf spring used for experiment is made up of Steel. The composition of material is $0.91 \mathrm{C} \%, 1.80$ SI\%, $0.70 \mathrm{Mn} \%, 0.045 \mathrm{P} \%, 0.045 \mathrm{~S} \%$. Before testing of the leaf spring Shot Peening is done on all leaves. The leaves used are in Hardened and tempered state.

Table No. 01

\begin{tabular}{|l|l|}
\hline Parameter & Value \\
\hline Total length of spring & $1540 \mathrm{~mm}$ \\
\hline $\begin{array}{l}\text { No. of full length leaves } \\
\text { (Master Leaf) }\end{array}$ & 01 \\
\hline Thickness of leaf & $13 \mathrm{~mm}$ \\
\hline Width of leaf spring & $60 \mathrm{~mm}$ \\
\hline Ultimate tensile strength & $1680-2200 \mathrm{Mpa}$ \\
\hline Tensile yield & $1540-1750 \mathrm{Mpa}$ \\
\hline Number of graduated leaves & 05 \\
\hline
\end{tabular}

\section{FEA Analysis}

C. 1. Total Deformation of Leaf Spring

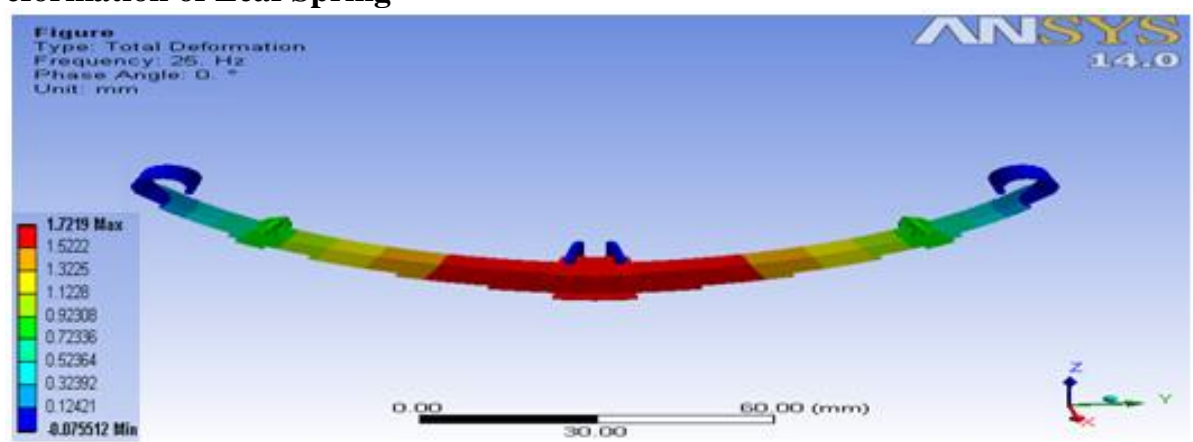




\section{2. Equivalent Stress of Leaf Spring}

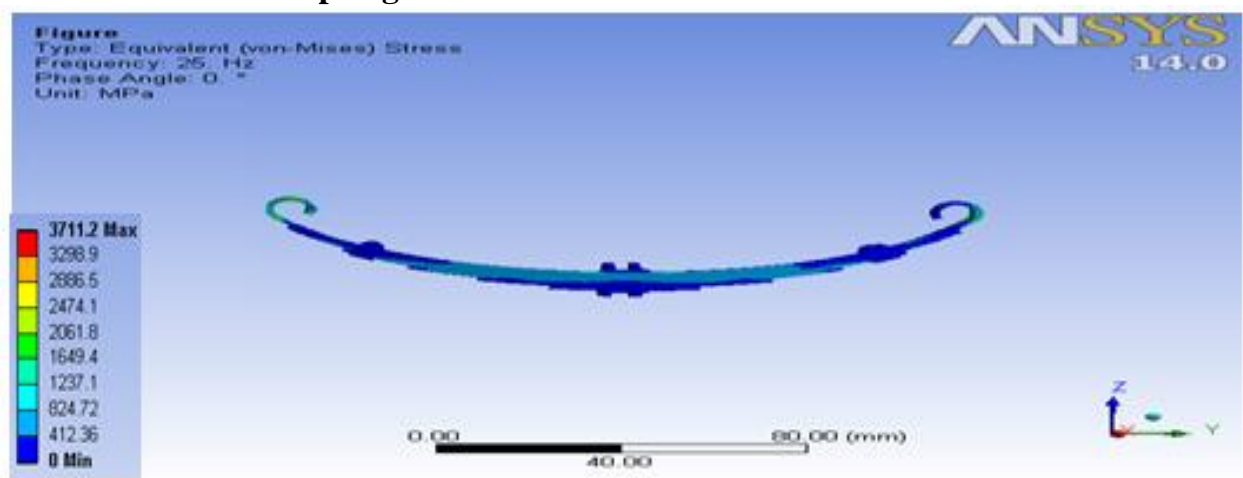

\section{3Equivalent Elastic Strain of Leaf Spring}

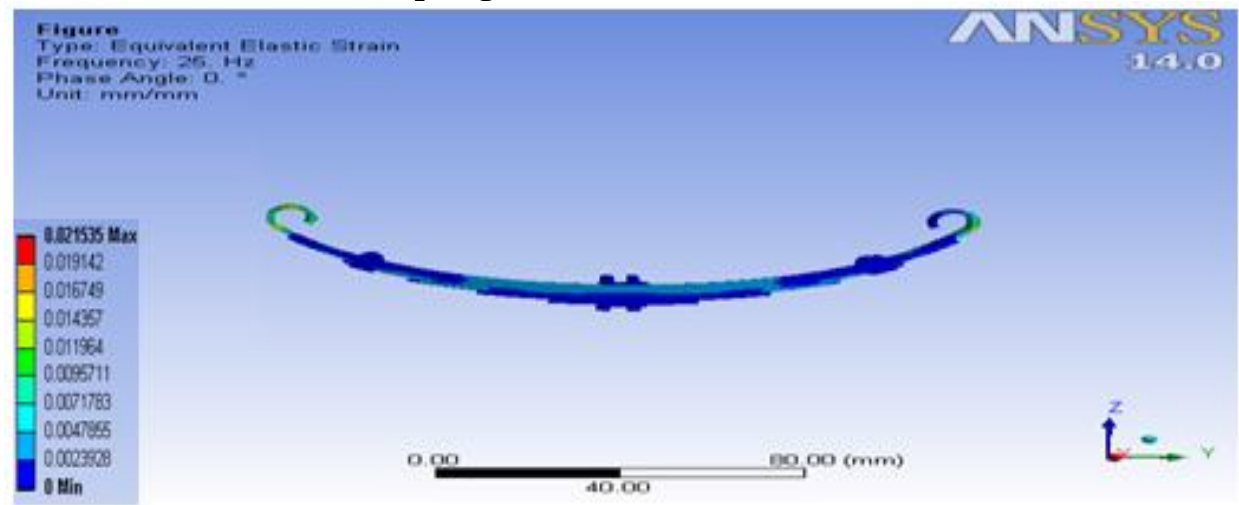

C. 4Graphical Representation of Frequency response of Stress

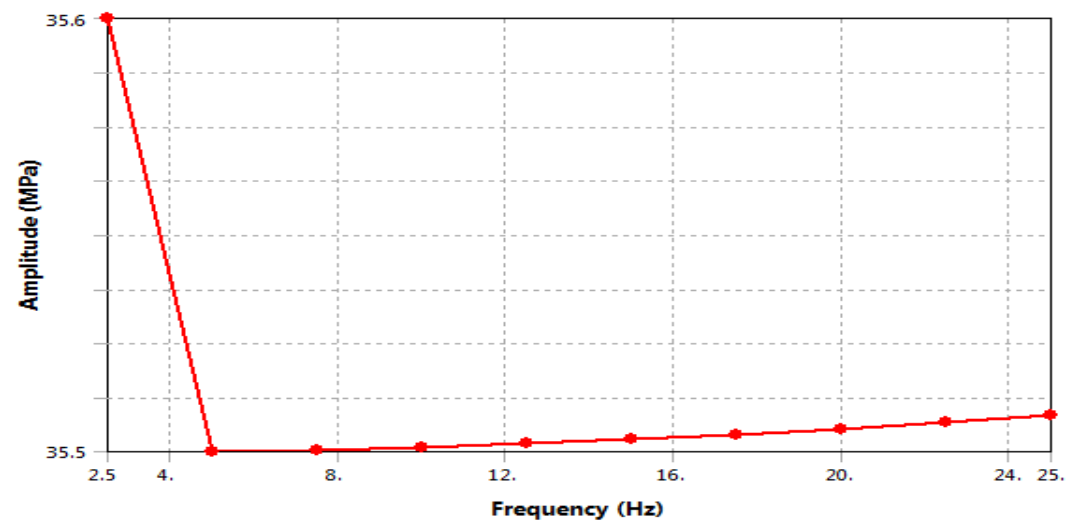

C.5 Graphical Representation of Frequency response of Strain

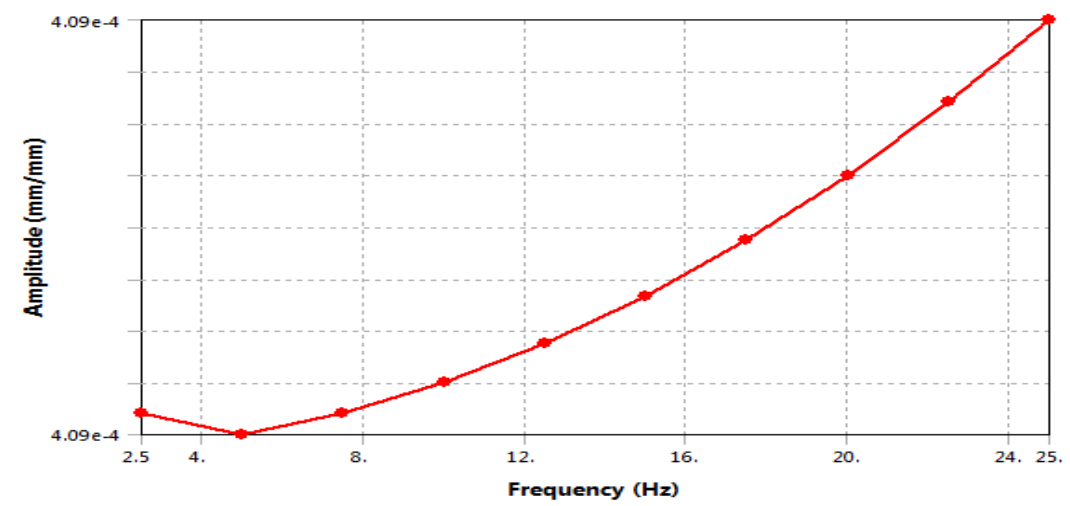




\section{6 Graphical Representation of Frequency response of Deformation}

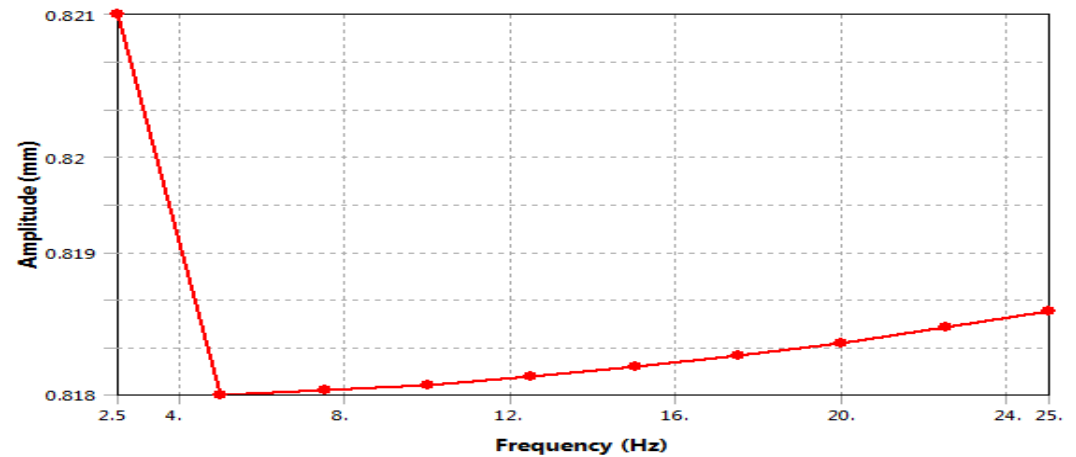

III. Result

Table No. 02: Maximum and Minimum Values of Leaf Spring

\begin{tabular}{|l|l|l|l|}
\hline \multirow{2}{*}{ Sr.no. } & \multirow{2}{*}{ Object Name } & Result \\
\cline { 3 - 4 } & & Minimum & Maximum \\
\hline 1 & Total Deformation & $0 . \mathrm{mm}$ & $1.7219 \mathrm{~mm}$ \\
\hline 2 & Directional deformation & $-0.0755 \mathrm{~mm}$ & $1.7219 \mathrm{~mm}$ \\
\hline 3 & Equivalent Stress & $0 . \mathrm{MPa}$ & $3711.2 \mathrm{MPa}$ \\
\hline 4 & Equivalent Elastic Strain & $0 . \mathrm{mm} / \mathrm{mm}$ & $0.021535 \mathrm{~mm} / \mathrm{mm}$ \\
\hline 5 & Shear Stress & $0 \mathrm{MPa}$ & $2129.4 \mathrm{MPa}$ \\
\hline
\end{tabular}

Table No. 03

\begin{tabular}{|l|l|l|l|l|l|}
\hline Object Name & $\begin{array}{l}\text { Stress Frequency } \\
\text { Response }\end{array}$ & $\begin{array}{l}\text { Frequency } \\
\text { Response strain }\end{array}$ & $\begin{array}{l}\text { Frequency Response } \\
\text { deformation }\end{array}$ & $\begin{array}{l}\text { Phase Response } \\
\text { stress }\end{array}$ & $\begin{array}{l}\text { Phase Response } \\
\text { strain }\end{array}$ \\
\hline $\begin{array}{l}\text { Maximum } \\
\text { Amplitude }\end{array}$ & $35.647 \mathrm{MPa}$ & $4.09 \mathrm{e} 4 \mathrm{~mm} / \mathrm{mm}$ & $0.821 \mathrm{~mm}$ & $\begin{array}{l}0.81837 \\
\mathrm{MPa}\end{array}$ & $\begin{array}{l}4.09 \mathrm{e}-0.004 \\
\mathrm{~mm} / \mathrm{mm}\end{array}$ \\
\hline Frequency & $5 . \mathrm{Hz}$ & $5 \mathrm{~Hz}$ & & $180^{\circ}$ & \\
\hline Phase Angle & $180^{\circ}$ & $180 .^{\circ}$ & $-35.506 \mathrm{MPa}$ & - \\
\hline Real & -35.647 & $\begin{array}{l}-4.09 \mathrm{e} .004 \\
\mathrm{~mm} / \mathrm{mm}\end{array}$ & $0.8216 \mathrm{~mm}$ & $0 \mathrm{MPa}$ & $0 \mathrm{~mm} / \mathrm{mm}$ \\
\hline Imaginary & $0 \mathrm{~mm} / \mathrm{mm}$ & $0 \mathrm{~mm}$ & $25 . \mathrm{Hz}$ & \\
\hline Reported Frequency & $25 \mathrm{~Hz}$ & &
\end{tabular}

\section{Conclusion}

In this thesis report,FEM approach has used for predicting the stress and deformation .A parametric study is also made by varying the load to investigate their effect on the stress of leaf spring .A frequency response graph is plotted to analyse the effect of Stress, Strain and Deformation.. The stiffness of whole system does not decreases with the increase in frequency which guarantees the reliability of the selected material of leaf spring. The combination of frequency and amplitude is found to be most efficient method for reducing or controlling applied force which generate stress.

\section{References}

[1]. Sugiyama et al [2006] Fatigue of Composites - Fatigue Modulus Concept and Life Prediction Journal of Composite Materials,

[2]. Fancheret al[1978] Composite Materials Design and Processes for Automotive Applications. The ASME Winter Annual Meeting, San Francisco.

[3]. Cebon, D [1986] Simulation of the response of leaf springs to broad band random excitation.Vehicle System Dynamics,

[4]. Hoyle, [2004] "Evaluation of a Multi-Leaf Hybrid Springs for Automotive Suspensions" SAE paper series, 2004-01-0782

[5]. MouleeswaranSenthil Kumar, SabapathyVijayarangan, [2007] " Analytical And Experimental Studies On Fatigue Life Prediction Of Steel And Composite Multi-Leaf Spring For Light Passenger Vehicles Using Life Data Analysis" Materials Science . Vol.13.No.2.

[6]. Erdogan Kilic [2006] "Analysis of composite leaf springs", http:// www.elsevier.com

[7]. C.K. Clarke and G.E. Borowski [2012] "Evaluation of a leaf spring failure" ASM International 1547-7029

[8]. Zhu Jianbao,Zhang Weibo [2008] (College of Mechanical Engineering and Automation,FuzhouUniversity,Fuzhou 350002,China);Optimized simulation design of taper leaf spring based on particle swarm optimization algorithms and ANSYS[J];Journal of Fujian University of Technology.

[9]. Kumar Krishan and Aggarwal M.L[2011] A Finite Element Approach for Analysis of a Multi Leaf Spring using CAE Tools Research Journal of Recent Sciences ISSN 2277-2502Vol. 1(2), 92-96, Feb. Res.J.Recent Sci.

[10]. S G HarinathGowd E VenugopalGoud[2012] "Static Analysis Of Leaf Spring"Issn: 0975-5462 Vol. 4 No.08 August "International Journal Of Engineering Science And Technology (Ijest)"

[11]. RanjeetMithari, Amar Patil, Prof. E. N. Aitavade [2012]“Analysis Of Composite Leaf Spring By Using Analytical \&Fea”Issn: 0975-5462 Vol. 4 No.12 December 2012 "International Journal Of Engineering Science And Technology (Ijest)"

[12]. V.Pozhilarasu, Dr. T.Parameshwaran Pillai [2012]"Performance Comparison Of Conventional And Composite Leaf Spring"Issn: 
0975-5462 Vol. 4 No.12 December "International Journal Of Engineering Science And Technology (Ijest)"

[13]. ThimmegowdaRangaswamy., SabapathyVijayarangan, [2005] Otimal Sizing And Stacking Sequence Of Composite Drive Shafts Materials Science Vol. 11, No. 2.

[14]. Tirupathi R. Chandrupatla\& Ashok D.Belegundu, [2005] “Introduction to Finite Elements in Engineering”. Third Edition- Pearson Education Pvt. Ltd.

[15]. S.S.Rao, [2001] "The Finite Element Method in Engineering". Third Edition- Butterworth Heinemann Publications.

[16]. .V.S.Sundarajamoorthy, N.Shanmugam [2000] "Machine Design"- Eighth Edition- Published by M.Sethuraaman, Anuradha Agencies.

[17]. O.P.Khanna, [1999] "Material science and metallurgy"-First edition Dhanapati Rai Publications. 